\title{
Robótica com Materiais Recicláveis e a Aprendizagem Significativa no Ensino da Matemática: Estudo Experimental no Ensino Fundamental
}

\author{
Icleia Santos $^{1}$, Luciano Frontino de Medeiros $^{2}$ \\ ${ }^{1,2}$ Programa de Mestrado em Educação e Novas Tecnologias - Centro Universitário \\ Internacional UNINTER$$
\text { Curitiba - PR - Brazil }
$$ \\ icleias14@gmail.com, luciano.me@uninter.com
}

\begin{abstract}
Robotics as a pedagogical tool has been evidenced as a valuable resource for recovering interest, creativity, imagination and logical reasoning by students and its application is justified by helping to develop critical thinking, motor coordination, and a sense of belonging in the student. The objective of this research was to verify the effectiveness of Robotics as a pedagogical tool, based in a causal-comparative research using Inferential Statistics, in third year students of a fundamental public school in geometry content, particularly geometric solids. The research was carried out in two groups of students and the content was worked in the same way in the two classes, being that the revision of the content in one of them was based on use of Robotics. Evaluations were applied in both groups at three moments and, at the end, it was verified that the group which received revision of the content with Robotics had a significant increase in grades.
\end{abstract}

Resumo. A Robótica como ferramenta pedagógica tem se mostrado um recurso fundamental para o resgate do interesse, da criatividade, da imaginação e do raciocínio lógico dos alunos. Sua aplicação se justifica por auxiliar no desenvolvimento do pensamento crítico, coordenação motora, aprimoramento do espírito de equipe e um sentimento de pertinência no aluno. O objetivo dessa pesquisa foi verificar a efetividade do uso da Robótica como ferramenta pedagógica, com base em uma pesquisa causalcomparativa utilizando Estatística Inferencial, em alunos do terceiro ano do ensino fundamental quanto ao conteúdo de geometria, em particular os sólidos geométricos. A pesquisa foi realizada em duas turmas de terceiro ano, o conteúdo foi trabalho da mesma maneira nas duas turmas, sendo que a revisão do conteúdo em uma delas foi feita com a utilização da Robótica. Aplicaram-se avaliações em três momentos nas duas turmas e, ao final, verificou-se que a turma que recebeu revisão do conteúdo com Robótica teve um aumento significativo no seu aproveitamento.

\section{Introdução}

A tecnologia é fundamental na sociedade atual, e as crianças, desde muito cedo, têm acesso por meio de vários dispositivos, nos quais podem jogar, acessar a internet e ter contato com vários tipos de informações. Porém, quando são meras usuárias, a sua participação se torna muito restrita, fazendo delas na maior parte do tempo simples expectadoras de imagens e situações que lhe são apresentadas. Eventualmente, perdem sua concentração, distraindo-se de seus deveres escolares pelo fascínio dos recursos disponíveis, na condição de atividades prontas e limitadoras. Nesse contexto, o pensar, o criar e o imaginar não estão necessariamente sendo exigidos, podendo haver, como resultado na situação limite a perda do timing do desenvolvimento do raciocínio, da criatividade e do fazer sonhar.

A escola, como meio de produzir o aprendizado, procura utilizar meios para incentivar e resgatar o interesse dos alunos com relação aos conteúdos que fazem parte do 
currículo, sempre buscando tornar a sala de aula mais motivadora. A motivação é um dos principais fatores que determinam o comportamento do ser humano. Para Perrenoud (2000 apud Moraes, 2010), o primeiro passo para a aprendizagem é a motivação. As aulas que incluem atividades lúdicas são mais prazerosas, cativam e possibilitam a aprendizagem significativa, por permitirem a expressão dos desejos e vontades dos estudantes.

$\mathrm{Na}$ busca sobre trabalhos correlatos alinhados ao tema desta pesquisa, identificaram-se iniciativas para a introdução da Robótica, seja no ensino fundamental ou médio (Barbosa et al., 2015; Guedes, Guedes, \& Castro, 2013), porém fundamentados no uso de kits LEGO. Propostas para reuso de materiais tecnológicos para a Robótica também tem sido relatados (Celinski et al, 2012), porém fora do contexto do Ensino Fundamental. Outros trabalhos centram-se no ensino de programação com plataformas robóticas de baixo custo (Medeiros Filho \& Gonçalves, 2008; Sousa et al., 2016). Entretanto, não se identificou estudos envolvendo especificamente a avaliação da aprendizagem pela aplicação da Robótica no Ensino Fundamental, utilizando metodologia quali-quantitativa baseada em Estatística Inferencial. A intenção do trabalho aqui relatado busca, portanto, trilhar pela confirmação mensurável baseada em estatística daquilo que empiricamente, ou por meio de estudos predominantemente qualitativos, tem-se alcançado com a aplicação da Robótica nas estratégias de ensino e aprendizagem.

\section{Robótica na Educação}

A Robótica é definida como uma área do conhecimento relacionada com o controle e a construção de robôs. Possui princípios básicos da mecânica, cinemática, automação, hidráulica, informática e inteligência artificial. Como ciência, pode ser considerada como a aplicação do conjunto dos sistemas eletro-mecânico-pneumático-hidráulicos que interagem com o mundo real com ou sem intervenção dos humanos. A robótica pertence ao grupo das ciências informáticas e é considerada multidisciplinar, pois agrupa e aplica conhecimentos de microeletrônica (peças eletrônicas do robô), engenharia mecânica (projeto de peças mecânicas do robô) e física cinemática (Silva et al., 2008).

A palavra "robot" deriva da palavra tcheca robotnik, que significa "servo" (Zilli, 2004, p. 37). Nesse sentido, ou de que ela é uma servidora de tarefas, a Robótica ou o uso de robôs na educação, como auxiliar do professor, pode promover um ambiente de aprendizagem, no qual o aluno aprende a pesquisar novos conhecimentos, buscando desenvolver seu raciocínio lógico, habilidades manuais, investigação e compreensão, resolução de problemas por meio de erros e acertos, dentre outros (Zilli, 2004, p. 40). Na área da educação, Seymour Papert (1985) utilizava a matemática como um meio para compreender como as crianças aprendem e pensam. Aplicou os princípios da Robótica na Educação com o auxílio do computador a fim de prover um facilitador atrativo no processo de aprendizagem da matemática para as crianças, surgindo assim 0 Construcionismo: o aluno como protagonista do seu aprendizado, construindo o seu próprio conhecimento por intermédio de alguma ferramenta (Papert, 2008).

A Robótica, enquanto meio de aprendizagem, é um conjunto de processos e procedimentos envolvendo uma proposta de aprendizagem que se vale de dispositivos robóticos como tecnologia de mediação para a construção do conhecimento. Desta forma, a Robótica, referida como meio de aprendizagem, não fala da tecnologia ou dos artefatos robóticos em si, nem do ambiente físico onde as atividades são desenvolvidas. Refere-se sim à proposta de possibilidades metodológicas de uso de tecnologias informáticas e robóticas no processo de ensino e aprendizagem (Mill \& César, 2010).

A intenção de eventualmente trazer dispositivos autômatos para a aprendizagem em sala de aula é que eles sejam artefatos cognitivos, os quais os alunos utilizam para 
VI Congresso Brasileiro de Informática na Educação (CBIE 2017)

Anais do XXIII Workshop de Informática na Escola (WIE 2017)

explorar e expressar suas próprias ideias. Seriam "um-objeto-para-pensar-com" (Papert, 1985, p. 26). Na visão de Papert, o indivíduo constrói e produz o conhecimento por meio da interação com o ambiente em que ele vive. Este sujeito que aprende, pensa, mesmo sem ser "ensinado", está em constante atividade na interação com o ambiente que lhe é propiciado.

As crianças parecem ser aprendizes inatos. Bem antes de irem a escola elas já apresentam uma vasta gama de conhecimento que foram adquiridos por um processo que chamarei "aprendizagem Piagetiana" ou "aprendizado sem ensino"(Papert, 1985, p. 20).

Ao considerar que as crianças já possuem uma gama de conhecimentos que foram adquiridos na interação com o ambiente em que ela vive e que esta interação tem influência direta com a aprendizagem, o autor propõe a inserção de "objetos-para-pensarcom", ou seja, objetos que facilitem e/ou possibilitem a construção de novos conhecimentos. Sendo assim, a Robótica pode ser vista como um objeto potencial de aprendizagem.

Para o desenvolvimento da aplicação da Robótica no contexto desse trabalho, foram usados materiais reaproveitados, para contextualizar com a premissa de que o aluno deve encontrar formas de aperfeiçoar os recursos em todas as áreas de seu mundo: em casa, no trabalho, na escola, etc. As crianças devem aprender a conviver com esta realidade, reaproveitando e reciclando materiais. Por isso, a proposta de reutilização nas aulas em que se usa a Robótica também contribui para ensinar as crianças a darem novos destinos para esses materiais. Ao instigar o aluno a observar, abstrair e inventar, criando seus modelos a partir de diversos materiais que lhe são apresentados, essas capacidades adicionais serão desenvolvidas. Os materiais que podem ser usados para essa parte das atividades são os mais variados: peças de brinquedos, eletrodomésticos e eletrônicos danificados, circuitos eletrônicos dos mais variados, etc.(Maisonnette, 2006).

Assim, a Robótica como ferramenta pedagógica se justifica por auxiliar no desenvolvimento do pensamento crítico, coordenação motora, aprendizagem por meio do erro e acerto, aprimoramento do espírito de equipe, companheirismo e o surgimento de um sentimento de orgulho no aluno na montagem de um dispositivo que foi construído por suas próprias mãos. Com o uso da Robótica, o aluno, terá noções do funcionamento do dispositivo criado por ele e de como pode alterar as decisões do objeto a ser estudado, dentro da limitação da tecnologia aplicada.

Como pressuposto teórico, a pesquisa está embasada na aprendizagem significativa de David Ausubel: A partir de um conceito geral, preexistente na estrutura cognitiva, acontece a construção de um novo conhecimento relevante para o aluno pelo relacionamento de novas informações que são ancoradas aos conceitos prévios. Estes conceitos prévios são denominados "subsunçores": pontos de fixação ou ancoradouros. O resultado de tal relacionamento do material com a estrutura cognitiva se reflete no significado psicológico que também embute elementos do modo de ser do aluno. Portanto, para a aprendizagem significativa, o material de apoio deve ter potencial de significação para o aluno (Ausubel, 2000, p. 1). A Robótica se insere de forma peculiar neste contexto por manifestar alto potencial de significação de conteúdos para os aprendizes.

\section{Metodologia da Pesquisa}

Este trabalho contempla uma pesquisa experimental, quali-quantitativa e causal comparativa (Moreira \& Caleffe, 2008, p. 73), sobre os efeitos da aplicação da Robótica Educacional como ferramenta pedagógica para o ensino de matemática, no conteúdo de geometria em duas turmas do $3^{\circ}$ ano do Ensino Fundamental de uma Escola Pública 
Municipal: A (Manhã) e B (Tarde), sendo a faixa etária entre 7 e 8 anos de idade, completando durante o ano de 2017. As turmas eram mistas (meninos e meninas). O protocolo de pesquisa contemplou um sorteio para decidir em qual dessas turmas seria aplicado os conteúdos com a intervenção da Robótica. A turma sorteada foi a B, escolhida como turma de trabalho e, por consequência, a turma A ficou como a turma de controle. $\mathrm{O}$ plano de aula com os conteúdos a serem ministrados foi o mesmo para as duas turmas e também a mesma professora ministrou as aulas da mesma forma, já que as turmas são de turnos diferentes. O mesmo planejamento foi utilizado para as duas turmas e foram realizadas avaliações diagnósticas em três momentos, antes da apresentação do conteúdo, logo após a apresentação do conteúdo e depois da revisão do conteúdo. Na revisão do conteúdo, para a turma A, a professora fez a revisão da maneira rotineira, enquanto que para a turma B a professora utilizou a Robótica, desenvolvendo oficinas de construção de robôs com sólidos geométricos.

O planejamento das aulas estava de conformidade com o currículo proposto pela Secretaria de Educação, abrangendo o eixo em "Geometria: Espaço e Forma", com os seguintes tópicos abordados: i) obtenção de figuras planas presentes nos objetos e sólidos geométricos de propriedades referentes a forma: circulares, quadradas, retangulares e triangulares; ii) representação geométrica de figuras espaciais e planas, identificação e nomeação; e iii) classificação dos sólidos geométricos (Costa \& Teixeira, 2015).

$\mathrm{Na}$ proposta pedagógica foi planejada uma série de atividades, sendo a primeira um diagnóstico relativo ao conhecimento das formas. A seguir, foram apresentados os sólidos geométricos com o uso de diferentes exemplos práticos para identificar as formas. Como passo seguinte, os alunos deveriam construir os planos em papel para a montagem das figuras sólidas. O passo da intervenção da Robótica contou com a apresentação de robôs montados previamente pela equipe de suporte tecnológico do grupo de pesquisa do qual os autores deste trabalho participam, com materiais recicláveis e reutilizáveis, evidenciando as diversas formas geométricas: robô tartaruga, robô esfera-pêndulo, robô esfera-giratório, robô pirâmide, robô paralelepípedo grande, robô cubo com som e LED, robô cone e robô triângulo desenhista.

Os robôs foram construídos com motores de corrente contínua reaproveitados de equipamentos eletrônicos e com alimentação de pilhas AA. Os alunos manipularam os robôs, aprendendo as formas e as funções que cada um desempenhava. Posteriormente, foram desenvolvidas oficinas para a montagem de robôs pelas equipes de alunos utilizando as formas geométricas aprendidas. A professora forneceu a planificação dos sólidos, nos quais, depois de montados a equipe poderia pintar e decorar à sua maneira. Foi explicado que, após o término da confecção do mesmo, ele iria ganhar um movimento simples, sendo fixado em uma base composta de rodas com motor e pilhas.

Os alunos foram incentivados também a batizarem suas criações, determinarem as ações que eles seriam capazes de executar (ações pertencentes ao campo da imaginação) e definirem um custo estimado para os seus robôs. Estas atividades visavam ao estabelecimento de um sentimento de que os robôs pertenciam a seus idealizadores, aqueles que definiram as suas funções.

\section{Apresentação dos resultados}

A coleta de dados para a pesquisa causal comparativa envolveu as duas turmas do $3^{\circ}$ ano do Ensino Fundamental em turnos diferentes, conforme já descrito. A turma de controle contou com 24 alunos, enquanto a turma de trabalho com 26 alunos. A avaliação diagnóstica apresentada aos alunos foi a mesma, composta de 19 itens versando sobre o 
VI Congresso Brasileiro de Informática na Educação (CBIE 2017)

Anais do XXIII Workshop de Informática na Escola (WIE 2017)

assunto "sólidos geométricos", com todas as respostas tendo peso igual. Atribuiu-se uma nota de 0 a 10 , proporcional ao número de acertos.

Os dados coletados consistiram nas notas obtidas pelos alunos nas três avaliações (inicial, intermediária e final), os quais foram tabulados e processados no software Excel ${ }^{\circledR}$ da Microsoft $\odot$ a fim de obter as curvas normais amostrais, de acordo com a teoria da Estatística Inferencial.

$\mathrm{Na}$ apresentação dos resultados, plotou-se as curvas normais das duas situações no mesmo gráfico com o objetivo de demonstrar a linha de raciocínio que será explicada na seção referente à avaliação dos resultados da pesquisa.

\subsection{Avaliação Inicial}

De cunho diagnóstico, foi aplicada nas duas turmas antes dos alunos terem contato com o conteúdo de Sólidos Geométricos. Observou-se que, conforme esperado, o desempenho das turmas foi baixo, com média de notas em torno de 2,5. As curvas normais baseadas nos dados coletados demonstraram que a maior expectativa é que as notas dessas amostras se situem aproximadamente entre 1,0 e 4,0, como pode ser constatado na figura 1 .

A interpretação da figura 2 mostra que a hipótese nula foi validada nos quatro testes de decisão (grau de significância e erro uni-caudal, grau de significância e erro bicaudal - a hipótese nula só é válida se os quatro testes derem resultado afirmativo), indicando que tanto a turma $\mathrm{A}$ quanto a $\mathrm{B}$ pertencem a uma mesma população para a situação de aplicação da avaliação antes da apresentação do conteúdo de sólidos geométricos.

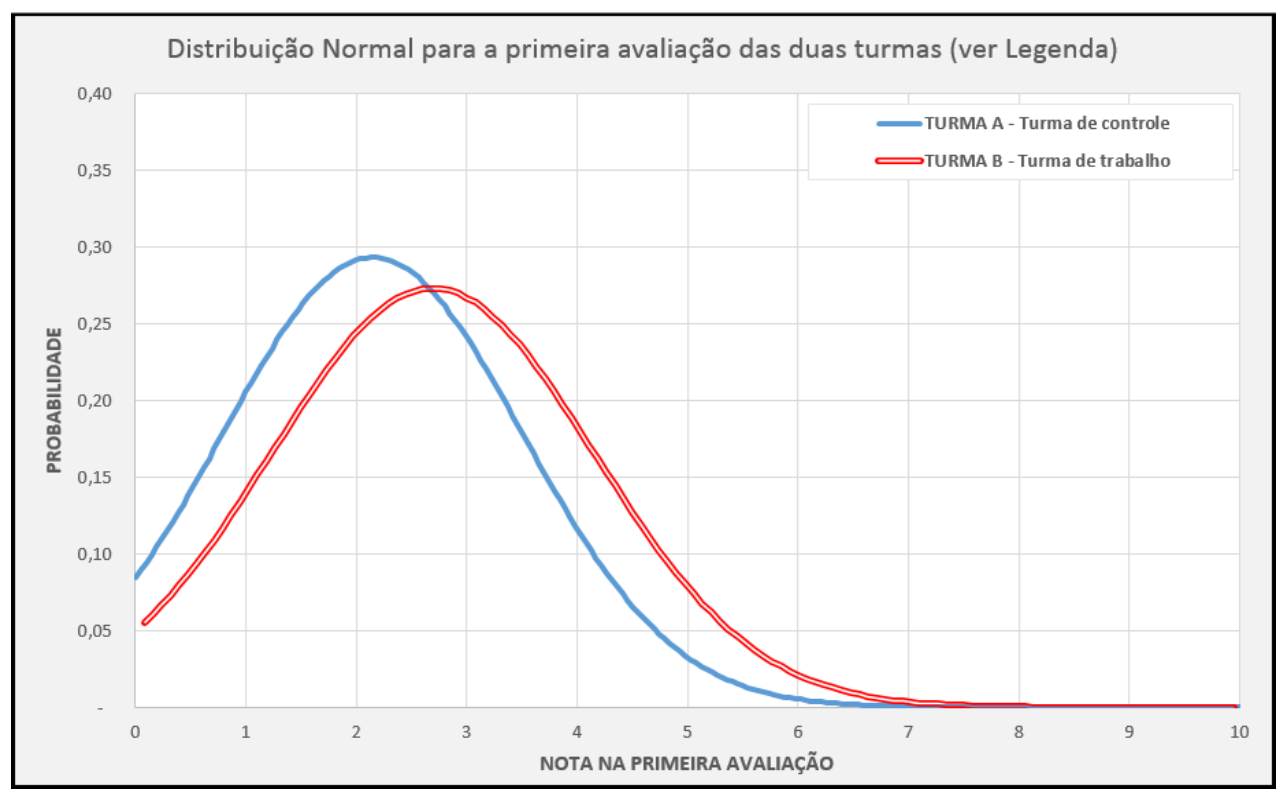

\begin{tabular}{|l|l|}
\hline TURMA A (Turma de controle) & TURMA B (Turma de trabalho) \\
\hline Média Aritmética $\quad \mu=2,15$ & Média Aritmética $\quad \mu=2,69$ \\
\hline Desvio Padrão $\quad \sigma=1,36$ & Desvio Padrão $\quad \sigma=1,46$ \\
\hline Quantidade de amostras $\mathrm{n}=24$ & Quantidade de amostras $\mathrm{n}=26$ \\
\hline
\end{tabular}

Figura 1. Curvas Normais com os resultados da Avaliação Inicial, Turmas A e B, com os parâmetros descritos abaixo. 
VI Congresso Brasileiro de Informática na Educação (CBIE 2017)

Anais do XXIII Workshop de Informática na Escola (WIE 2017)

Para o teste inferencial, aplicou-se o teste $\mathrm{t}$ de Student nos dois conjuntos de amostragem, considerando a hipótese nula como sendo a uniformidade de comportamento para as turma A e B. O resultado obtido está mostrado na figura 2.

\subsection{Avaliação Intermediária}

Esta avaliação foi aplicada nas duas turmas logo após os alunos terem contato com o conteúdo de sólidos geométricos. Nesta fase do processo de ensino e aprendizagem, observamos uma melhora no rendimento das turmas, como pode ser identificado a partir da análise das curvas normais na figura 3.

\begin{tabular}{|c|c|c|c|c|}
\hline \multicolumn{5}{|c|}{ Teste-t: duas amostras presumindo variâncias equivalentes } \\
\hline \multicolumn{3}{|c|}{ ERRO PRESUMIDO NA AVALIAÇÃO } & 0,05 & $\alpha$ \\
\hline & NOTAS A & $1 \mathrm{~A}$ & \multicolumn{2}{|c|}{ NOTAS AV1 B } \\
\hline Média & 2,1491 & $\mu_{1}$ & 2,6923 & $\mu_{2}$ \\
\hline Variância & 1,8527 & $\sigma_{1}$ & 2,1347 & $\sigma_{2}$ \\
\hline Observações & 24 & $\eta_{1}$ & 26 & $\eta_{2}$ \\
\hline Variância agrupada & 1,9996 & $\sigma \mathrm{t}$ & & \\
\hline Hipótese da diferença de média & 0,0000 & $\mathbf{H}$ & & \\
\hline Grau de liberdade & 48 & gl & & \\
\hline Stat t & $-1,3570$ & $\mathbf{S}$ & & \\
\hline$P(T<=t)$ uni-caudal & 0,0906 & $\mathrm{Pu}$ & & \\
\hline t crítico uni-caudal & 1,6772 & $\mathrm{TCu}$ & & \\
\hline $\mathrm{P}(\mathrm{T}<=\mathrm{t})$ bi-caudal & 0,1811 & $\mathbf{P b}$ & & \\
\hline t crítico bi-caudal & 2,0106 & $\mathrm{TCb}$ & & \\
\hline
\end{tabular}

Figura 2. Teste t de Student, para os resultados das avaliações iniciais, turmas A e B.

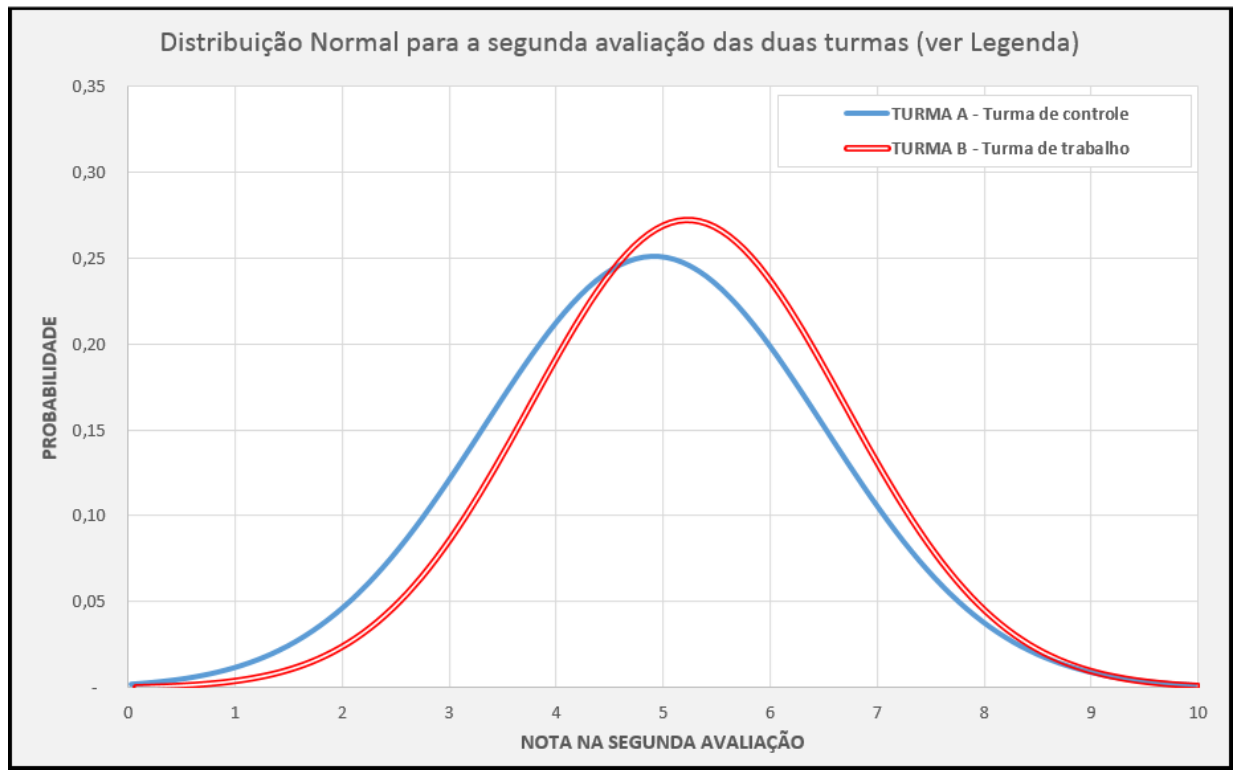

\begin{tabular}{|l|l|}
\hline TURMA A (Turma de controle) & TURMA B (Turma de trabalho) \\
\hline Média Aritmética $\quad \mu=4,91$ & Média Aritmética $\quad \mu=5,23$ \\
\hline Desvio Padrão $\quad \sigma=1,59$ & Desvio Padrão $\quad \sigma=1,47$ \\
\hline Quantidade de amostras $\mathrm{n}=24$ & Quantidade de amostras $\mathrm{n}=26$ \\
\hline
\end{tabular}

Figura 3. Curvas normais com os resultados da avaliação intermediária, turmas A e B. 
VI Congresso Brasileiro de Informática na Educação (CBIE 2017)

Anais do XXIII Workshop de Informática na Escola (WIE 2017)

Novamente, aplicou-se o teste $\mathrm{t}$ de Student sobre as amostragens tomadas nas duas turmas, considerando a hipótese nula a pertinência dos dois conjuntos de dados amostrais a uma mesma população. $\mathrm{O}$ resultado obtido pode ser analisado a partir dos dados na figura 4. A hipótese nula foi validada também para esta condição (resultado satisfatório para os quatro testes), indicando que as turmas A e B pertencem a uma mesma população para a situação de aplicação da avaliação após a apresentação do conteúdo de sólidos geométricos.

\begin{tabular}{|c|c|c|c|c|}
\hline \multicolumn{5}{|c|}{ Teste-t: duas amostras presumindo variâncias equivalentes } \\
\hline \multicolumn{3}{|c|}{ ERRO PRESUMIDO NA AVALIAÇÃO } & 0,05 & $\alpha$ \\
\hline & NOTAS A & $12 A$ & \multicolumn{2}{|c|}{ NOTAS AV2 B } \\
\hline Média & 4,9123 & $\mu_{1}$ & 5,2227 & $\mu_{2}$ \\
\hline Variância & 2,5212 & $\sigma_{1}$ & 2,1479 & $\sigma_{2}$ \\
\hline Observações & 24 & $\eta_{1}$ & 26 & $\eta_{2}$ \\
\hline Variância agrupada & 2,3268 & $\sigma \mathrm{t}$ & & \\
\hline Hipótese da diferença de média & 0,0000 & $\mathbf{H}$ & & \\
\hline Grau de liberdade & 48 & gl & & \\
\hline Stat $\mathrm{t}$ & $-0,7189$ & $\mathbf{S}$ & & \\
\hline $\mathrm{P}(\mathrm{T}<=\mathrm{t})$ uni-caudal & 0,2379 & $\mathrm{Pu}$ & & \\
\hline t crítico uni-caudal & 1,6772 & $\mathrm{TCu}$ & & \\
\hline$P(T<=t)$ bi-caudal & 0,4757 & $\mathrm{~Pb}$ & & \\
\hline t crítico bi-caudal & 2,0106 & $\mathrm{TCb}$ & & \\
\hline
\end{tabular}

Figura 4. Teste t de Student, para os resultados das avaliações intermediárias.

\subsection{Avaliação Posterior}

Esta avaliação foi aplicada na turma A logo após os alunos terem recebido a revisão do conteúdo de sólidos geométricos, usando a metodologia tradicional e na turma B com a revisão utilizando a Robótica como ferramenta pedagógica.

Em relação à turma $\mathrm{A}$, observa-se que a expectativa de melhor aproveitamento dos alunos, nesse caso, orbita a nota 6,0. Outro detalhe interessante é observar que a curva normal para este caso se apresenta acentuadamente estreita, decorrente do desvio padrão significativamente menor, indicando que o aproveitamento da turma nessa condição teria pouca expectativa de melhora, mesmo com grande esforço de repetição do conteúdo.

A análise dos resultados obtidos na turma B permite observar o elevado grau de aproveitamento, resultante do interesse despertado nos alunos. Observa-se que a expectativa de rendimento significativo ficou entre 8,0 e 10,0. É visível e evidente a vantagem que se obtém no rendimento da turma quando se usa a Robótica no reforço do conteúdo apresentado em sala de aula.

Como ponto central desta pesquisa, é válido ressaltar que a diferença de rendimento demonstra o resultado obtido pela aplicação da Robótica como ferramenta pedagógica, pois é o único parâmetro que diferenciou uma turma da outra. Percentualmente, obteve-se uma melhora de aproximadamente $50 \%$ na nota média quando comparados os dois cenários.

Mesmo com a clara diferença entre as duas curvas normais para tais resultados, foi efetuada uma nova aplicação do teste t de Student, ainda considerando a hipótese nula como a pertinência das duas turmas a uma mesma população.

O objetivo dessa aplicação era de que, com a não validação da hipótese nula, demonstrar que existiu um fator que distanciou os alunos pertencentes à turma $\mathrm{B}$ da 
VI Congresso Brasileiro de Informática na Educação (CBIE 2017)

Anais do XXIII Workshop de Informática na Escola (WIE 2017)

população de alunos que receberam os reforços de conteúdos pelos métodos tradicionais. Ou seja, pela dedução de que se obteve uma alteração nos resultados. Como a única diferença entre as duas turmas era o uso do novo recurso pedagógico, buscou-se assim confirmar a tese da validade do mesmo. O resultado obtido nesta aplicação do teste $t$ de Student está mostrado na figura 6 .

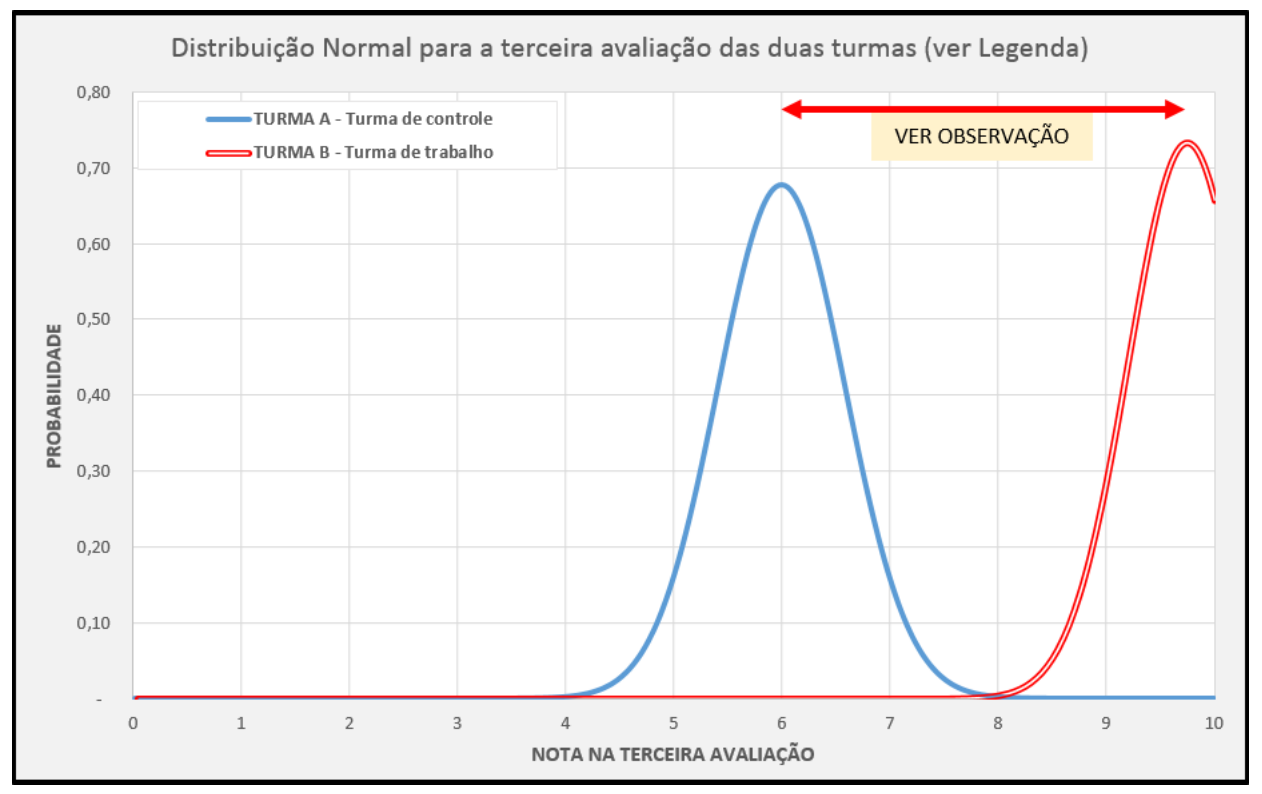

\begin{tabular}{|l|l|}
\hline TURMA A (Turma de controle) & TURMA B (Turma de trabalho) \\
\hline Média Aritmética $\quad \mu=6,00$ & Média Aritmética $\quad \mu=9,75$ \\
\hline Desvio Padrão $\quad \sigma=0,49$ & Desvio Padrão $\quad \sigma=0,54$ \\
\hline Quantidade de amostras $\mathrm{n}=24$ & Quantidade de amostras $\mathrm{n}=26$ \\
\hline
\end{tabular}

Figura 5. Curvas Normais com os resultados da Avaliação Final, Turmas A e B.

\begin{tabular}{|c|c|c|c|c|}
\hline \multicolumn{5}{|c|}{ Teste-t: duas amostras presumindo variâncias equivalentes } \\
\hline \multicolumn{3}{|c|}{ ERRO PRESUMIDO NA AVALIAÇÃO } & 0,05 & $\alpha$ \\
\hline & NOTAS A & $3 \mathrm{~A}$ & \multicolumn{2}{|c|}{ NOTAS AV3 B } \\
\hline Média & 5,9954 & $\mu_{1}$ & 9,1303 & $\mu_{2}$ \\
\hline Variância & 0,3460 & $\sigma_{1}$ & 7,2528 & $\sigma_{2}$ \\
\hline Observações & 23 & $\eta_{1}$ & 26 & $\eta_{2}$ \\
\hline Variância agrupada & 4,0198 & $\sigma \mathrm{t}$ & & \\
\hline Hipótese da diferença de média & 0,0000 & $\mathbf{H}$ & & \\
\hline Grau de liberdade & 47 & gl & & \\
\hline Stat t & $-5,4623$ & $\mathbf{S}$ & & \\
\hline $\mathrm{P}(\mathrm{T}<=\mathrm{t})$ uni-caudal & 0,0000 & $\mathrm{Pu}$ & & \\
\hline t crítico uni-caudal & 1,6779 & $\mathrm{TCu}$ & & \\
\hline$P(T<=t)$ bi-caudal & 0,0000 & $\mathrm{~Pb}$ & & \\
\hline t crítico bi-caudal & 2,0117 & TCb & & \\
\hline
\end{tabular}

Figura 6. Teste t de Student, para os resultados das Avaliações Posteriores.

A análise do resultado do teste mostra, portanto, que a hipótese nula não é mais válida (dos quatro testes, três deles não foram satisfatórios, portanto, invalidando a hipótese nula). Por consequência, é admitida a hipótese alternativa, o que dá a indicação de que as turma $\mathrm{A}$ e $\mathrm{B}$ não pertencem mais a uma mesma população, com referência à aplicação da avaliação após a revisão do conteúdo de sólidos geométricos. 
Desta forma, considerando o histórico mostrado pelos três resultados dos testes t de Student, pode-se concluir estatisticamente que a população dos alunos usada nesses estudos apresentava comportamento similar nas duas primeiras avalições, porém, um fator diferencial foi introduzido na terceira avaliação. O fator considerado foi o uso da Robótica como ferramenta pedagógica na turma $\mathrm{B}$, considerada como causa da diferenciação desses alunos em relação à população original.

\section{Análise dos Resultados da Pesquisa}

Com relação ao suporte quantitativo a esta pesquisa, foi adotada a estatística inferencial para auxiliar na análise dos dados, sendo evidenciada uma distribuição gaussiana das notas das amostras com variâncias equivalentes e utilizando-se o teste de hipótese paramétrico $t$ de Student. A hipótese nula foi definida pela similaridade das distribuições normais das notas médias obtidas entre as turmas. Desta forma, o teste de hipótese foi utilizado em três momentos: i) na avaliação inicial, onde se validou a hipótese nula, demostrando que as turmas estavam no mesmo nível de conhecimento antes da intervenção; ii) na avaliação intermediária, relativa à revisão dos conteúdos, houve também a validação da hipótese nula; e iii) na avaliação final, onde a hipótese nula foi invalidada, evidenciando-se portanto a diferença nas notas médias das turmas pelo efeito da intervenção da Robótica. Os resultados preliminares apontaram que o aprendizado do conteúdo de geometria obteve um avanço na nota média de $60 \%$, na medição sem intervenção, e $90 \%$ com a intervenção da Robótica.

\section{Considerações Finais}

As atividades com robótica propiciam ao aluno o desafio de encontrar soluções para as atividades proposta, estimula a criatividade, a imaginação, a resolução de conflitos internos e externos quando se encontra dificuldades para resolver problemas, ao mesmo tempo é motivadora, pois é algo de interesse onde se pode mexer e entender o que se passa na conexão de fios, e pode-se constatar o efeito quando se liga ou não dois fios conectados ao motor.

Por maior contato e mais imersos que sejam com relação à tecnologia atual, os alunos são predominantemente meros operadores onde apertam um botão liga/desliga, ou acessam um aplicativo para desenvolver atividades repetitivas. Assim, seu relacionamento com a tecnologia é mais de um expectador ou estando em um relacionamento superficial como jogador.

Com a Robótica, ele pode desenvolver algo concreto, compreender dentro do sistema como se movimenta o robô por meio de motores, ligações de fios. E principalmente, sentir que é ele o autor do movimento, da construção do seu modelo. Isto o motiva em busca do saber, criar, origina o despertar do aluno para suas capacidades que o instiga a querer descobrir mais sobre si mesmo e suas potencialidades.

No contexto desta pesquisa, constatou-se isso pela análise dos resultados sumarizados, demostrando a eficiência da Robótica como ferramenta pedagógica. Obtevese um ganho mensurável do aprendizado, evidenciado pela elevação das notas da avaliação após a intervenção com Robótica. Porém, outros fatores intangíveis (que não podemos mensurar em gráfico) devem ser considerados, tais como o entusiasmo, a alegria, o envolvimento, o compartilhar com os amigos de equipe, a imaginação, a criatividade, o sentimento de pertinência ao ser o criador do seu protótipo, o desenvolvimento motor, a tentativa até acertar, o não desistir para ver seu projeto pronto, dentre outros. 
VI Congresso Brasileiro de Informática na Educação (CBIE 2017)

Anais do XXIII Workshop de Informática na Escola (WIE 2017)

A partir dos resultados obtidos, abrem-se perspectivas para a extensão do estudo a outros conteúdos do currículo escolar usando a Robótica como ferramenta pedagógica, como sequência para trabalhos futuros.

\section{Referências}

Ausubel, D. (2000). Aquisição e Retenção de Conhecimentos: Uma Perspectiva Cognitiva. Plátano Edições Técnicas, 35.

Barbosa, F. C., Alexandre, M. L., Alves, D. B., Menezes, D. C., Campos, G. L., Nakamura, Y. S. N., ... Lopes, C. R. (2015). Robótica Educacional em Prol do Ensino de Matemática. In XXI Workshop de Informática na Escola (pp. 271-280). Maceió-AL. http://doi.org/10.5753/cbie.wie.2015.271

Celinski, T. M., Cerutti, D. M. L., Celinski, V. G., Cerutti, I. A., \& Ielo, F. G. de P. F. (2012). Robótica Educativa: Uma proposta para o reuso do lixo eletrônico em uma atividade de extensão universitária. In 4o Congresso Internacional de Educação, Pesquisa e Gestão.

Costa, C. E., \& Teixeira, M. A. P. (2015). Orientações Curriculares Municipais para a Educação Infantil. São José dos Pinhais-PR: Prefeitura Municipal de São José dos Pinhais. Retrieved from http://www.sjp.pr.gov.br/wpcontent/uploads/2013/04/ORIENTACOES-ED-INFANTIL-SJP-2016-ok-24-11.pdf

Guedes, A. L., Guedes, F. L., \& Castro, T. B. (2013). Perspectivas do uso da Robótica Educativa na Educação Infantil e no Ensino Fundamental. In II Congresso Brasileiro de Informática na Escola - XIX Workshop de Informática na Escola (pp. 410-414). Campinas-SP. http://doi.org/10.5753/CBIE.WIE.2013.410

Maisonnette, R. (2006). A Utilização dos Recursos Informatizados a partir de uma Relação Inventiva com a Máquina: A Robótica Educativa. Retrieved from http://www.proinfo.gov.br/upload/biblioteca.cgd/192.pdf

Medeiros Filho, D. A., \& Gonçalves, P. C. (2008). Robótica Educacional de Baixo Custo: Uma Realidade para as Escolas Brasileiras. In XXVIII Congresso da SBC (pp. 264273). Belém-PA.

Mill, D., \& César, D. (2010). Robótica pedagógica livre: sobre inclusão sócio-digital e democratização do conhecimento. Perspectiva, 27(1), 217-248.

http://doi.org/10.5007/2175-795X.2009v27n1p217

Moraes, M. C. (2010). Robótica Educacional : Socializando E Produzindo Conhecimentos.

Moreira, H., \& Caleffe, L. G. (2008). Metodologia da Pesquisa para o Professor Pesquisador. (Lamparina, Ed.) (2a. Ed). Rio de Janeiro: Lamparina.

Papert, S. (1985). LOGO: Computadores e Educação. (Brasiliense, Ed.). São Paulo.

Papert, S. (2008). A Máquina das Crianças: repensando a escola na era da informática. Porto Alegre: Artmed.

Silva, A. F. da, Guerreiro, A. M. G., Agaé, A., Pitta, R., Gonçalves, L. M. G., \& Aranibar, D. B. (2008). Utilização da Teoria de Vygotsky em Robótica Educativa. IX Congreso Iberoamericano De Informatica Educativa RIBIE.

Sousa, L. M. G., Costa, D. G., Martinez, A. C., Ribeiro, T. P., Couto, L. N., \& Souza, J. R. (2016). Ensino de Programação em Robótica Móvel no Ensino Fundamental e Médio. In V Congresso Brasileiro de Informática na Educação (pp. 399-402). Uberlândia-MG. http://doi.org/10.5753/cbie.wcbie.2016.399

Zilli, S. do R. (2004). A Robótica Educacional no Ensino Fundamental: Perspectivas e Práticas, 89. Disponível em <https://repositorio.ufsc.br/xmlui/handle/123456789/ 86930>. Acesso em 20/08/2017. 